\title{
LA EXCESIVA E IRREMEDIABLE HUMANIDAD DE LA VERDAD: LENGUAJE E HISTORIA EN EL NIETZSCHE DE LA FASE 1873-8
}

\author{
The Excessive and Irremediable Humanity of Truth: \\ Language and History in Nietzsche's 1873-8 era
}

César Inca Mendoza Loyola*

Recepción: 02-10-2018

Aceptación:09-10-2018

\begin{abstract}
RESUMEN
Dentro de la obra del joven Nietzsche, la secuencia que va desde el opúsculo Sobre verdad y mentira en sentido extramoral hasta Humano, demasiado humano, pasando por la Segunda Intempestiva: Sobre la utilidad y el perjuicio de la historia para la vida, nos permite ver la sostenidamente rápida evolución que tuvo la concepción nietzscheana de la verdad como constructo metafórico cuya dimensión práctica se valida como acción y contemplación afirmativas de la vida. Así, se postula a la filosofía como una labor de esclarecimiento de que vivir y pensar cómo se vive son, en realidad, la misma cosa. Además, en ese pensar se hace imprescindible plantear un trasfondo histórico para entender cómo se ha llegado a ser lo que es... y esa historia es, claro está, un constructo.
\end{abstract}

\section{Palabras clave}

Metáfora, historia, verdad, vitalidad.

\begin{abstract}
In Nietzsche's early works, the concatenation of the small essay On Truth and Lies in a Nonmoral Sense, his second Untimely Meditaion: On the Use and Abuse of History for Life and his book Human, all too Human, we can witness the sustained quickness in the evolution of the Nietzschean conception of truth as a metaphorical construct. Its validation rests on its practical dimension as life-affirming action and contemplation, and so, philosophy is declared as a labor of clarification of how living and thinking life are the same thing. Besides, this path of thought brings out the statement of our historical background as an essential item for our understanding of how we have come to be what we are... and of course, that previously mentioned historical background is a construct.
\end{abstract}

\section{Keywords}

Metaphor, history, truth, vitality.

* Docente de la Pontificia Universidad Católica del Perú y de la Universidad Antonio Ruiz de Montoya: cesarinca68@hotmail.com 


\section{INTRODUCCIÓN ${ }^{1}$}

Nietzsche hizo algo muy osado cuando declaró al inicio de su opúsculo Sobre verdad y mentira en sentido extramoral que "en algún apartado rincón del universo centelleante, desparramado en innumerables sistemas solares, hubo una vez un astro en el que animales inteligentes inventaron el conocimiento." (2015, p. 21) En este breve ensayo que data del verano de 1873 y que fue rápidamente olvidado por su propio autor, el mecanismo conceptual nietzscheano se puso rápidamente en marcha por la vía de su cuestionamiento radical de los estándares de verdad y objetividad en la historia de la filosofía y la ciencia, marcada por una terrible autocomplacencia de pretensiones metafísicas. El análisis del lenguaje como artificio convierte en ilusión a todo lo que se dice y piensa a través de él, incluso el amor a la verdad. Amor a la verdad es amor a lo fijo... pero ¿̇qué puede haber de fijo en el hombre, quien es una criatura de certezas inciertas en medio de tiempos siempre veleidosos? Solo puede darse la verdad como historia, autobiografía, mirada hacia el recorrido antes trazado para así poder dar un sentido a la obra futura, a la misión existencial, a la vida. Así las cosas, la historia se revela como construcción de significados y orientaciones morales que nos ayudan a centrar la experiencia de la vida misma. Habrá que ver qué tipo de historia es la que mejor cumple con la doble misión de hacernos olvidar lo vivido y reconstruir nuestra comprensión de lo que queda por vivir, pues solo así sirve la historia a la vida. Se trata de la historia crítica, la cual ejerce una continua crítica creativa de la vida y de sí misma, buscando lo heroico en lo nuevo mientras aprende a apreciar con nuevos ojos cada día a un pasado que ya no se pretende observar objetivamente, sino recrear desde una óptica estética. He aquí el motif central de la Segunda Intempestiva: Sobre la utilidad y el perjuicio de la historia para la vida (1874), el cual sirvió como acicate para las inquietudes multitemáticas vertidas en Humano, demasiado humano, publicado originalmente en 1878 con dedicatoria a Voltaire por el centenario de su muerte (el primer libro grande tras El nacimiento de la tragedia).

En la tercera parte de su autobiografía Ecce homo, Nietzsche se refiere a Humano, demasiado humano como un libro cuyo mismo título dice que donde los demás ven ideales, él detecta cosas inevitablemente humanas: "Una antorcha en las manos, la cual no da en absoluto una luz «vacilante», es lanzada, con una claridad incisiva, para que ilumine a ese inframundo del ideal." (III, §3) Tal como el propio autor señala en uno de los pasajes iniciales del libro en cuestión: "Todos los filósofos tienen el defecto común de partir del hombre actual y creer que con un análisis del mismo llegan a la meta. Involuntariamente, «el hombre» se les antoja como una aeterna veritas, como algo invariable en medio de toda la vorágine, como una medida cierta de las cosas." (I, \$2) Pero, con su apreciación del sentido histórico como la clave para interpretar y juzgar los conceptos establecidos sobre eso que llamamos lo real sobre raíces metafísicas, Nietzsche se siente preparado para plantear una alternativa insolente y excluyente ante tales conceptos. Aquí se inicia la misión nietzscheana de acabar con todos los fantasmas de la verdad tradicional para reivindicar la verdad

1 La presente ponencia está parcialmente inspirada en otra que ofrecí a fines de octubre del 2017 en el contexto del Congreso Internacional de Lingüística: Lingüística y Filosofía. La ponencia se titulaba "El lenguaje como construcción de "verdades" en el Nietzsche de 1873 y el 2do Wittgenstein". Aquí me concentraré en la parte de Nietzsche, centrándome en su producción filosófica realizada en el período indicado en el título. 
como el mañana... una construcción cada vez nueva para cada nuevo mañana. Así, comenzaremos la presente ponencia exponiendo el enfoque radicalmente escéptico con el que Nietzsche diseca el concepto estandarizado de verdad descubriendo en su núcleo más íntimo un mero artificio del lenguaje. En una segunda instancia, veremos cómo ve Nietzsche en la historia la clave más precisa del intelecto humano en su afán por descubrir eso que no podemos dejar de llamar verdad, una clave bastante "tramposa", por cierto. Por último, veremos cómo la modalidad crítica de la historia le da un norte muy bien definido a la concepción nietzscheana de verdad, el norte de hacer soportable y dichosa la vida, con lo cual la historia se revela como la fusión de experiencia de vivir y reflexión sobre esa experiencia misma. El rastreo nietzcheano que aquí emprendemos para esta labor exegética va por los textos Sobre verdad y mentira en sentido extramoral, la Segunda Intempestiva y Humano, demasiado humano. La importancia de esta tríada (armada un tanto arbitrariamente en cuanto a la omisión de las otras tres Intempestivas) radica en que a través de su secuencia se hila la maduración de la concepción nietzscheana de la historia como un constructo que refleja la importancia de ella como la verdad de la vida mirándose a sí misma.

\section{El invento del conocimiento desde el invento del lenguaje}

En el año 1873, Nietzsche elaboró un pequeño ensayo titulado Sobre verdad y mentira en sentido extramoral, un año después de su controvertido libro de debut El nacimiento de la tragedia, aunque recién en 1896 tuvo lugar su primera publicación. En el pasaje inicial de este ensayo, Nietzsche proclama el minuto más altanero y falaz de la «Historia Universal»: "En algún apartado rincón del universo centelleante, desparramado en innumerables sistemas solares, hubo una vez un astro en el que animales inteligentes inventaron el conocimiento" (2015, p. 21). Esta desafiante retórica de entrada, aunque exhibe un tenor epistemológico, no porta realmente la intención de proponer una epistemología sino una teoría del significado radicalmente nominalista desde la cual se nos muestre la dramática realidad de la impotencia de la epistemología misma: en efecto, es el lenguaje como herramienta crucial de construcción de significados el tema central del ensayo. ${ }^{2}$ Aquí, el lenguaje examina detenidamente sus propias raíces y se descubre como máscara que gesta y agrupa conceptos, siendo éstos un mero artificio motivado por impulsos nerviosos. Y no solo eso, también son manifestaciones del deseo de comunicar algo a otro... y solo eso, nada tienen que ver con lo que usualmente se entiende como "designación de algo que existe en el mundo". Siendo así que en la tradición epistemológica la posición del conocimiento se sostiene sobre la posibilidad del intelecto de apreciar y apresar un índice de la realidad objetiva del mundo y la consecuente exigencia de distinguir entre verdad y falta de ella (error, falsedad), Nietzsche se pregunta a sí mismo qué es, al fin y al cabo, la verdad:

\begin{abstract}
Una hueste en movimiento de metáforas, metonimias, antropomorfismos, en resumidas cuentas, una suma de relaciones humanas que han sido realzadas,
\end{abstract}

2 Aquí utilizamos la referencia al nominalismo en su sentido estandarizado a partir del legado de Guillermo de Ockham. Su propuesta ontológica de un universo estrictamente habitado "por elementos individuales, sin ningún vínculo real entre sí, no ordenables en términos de naturaleza o de esencia", obliga a los términos universales a ser "meros nombres y no una realidad y tampoco poseen un fundamento en la realidad concreta." (Reale y Antiseri, 1988, pp. 535-537) 
extrapoladas y adornadas poética y retóricamente y que después de un prolongado uso, un pueblo considera firmes, canónicas y vinculantes. Las verdades son ilusiones de las que se ha olvidado que lo son; metáforas que se han vuelto gastadas y sin fuerza sensible, monedas que han perdido su troquelado y no son ahora ya consideradas como monedas, sino como metal. (2015, p. 28)

En una suerte de tratado de paz mediante el cual pueden los hombres fundar las sociedades, se fija lo que ha de ser verdad en el sentido de la invención de "una designación de las cosas uniformemente válida y obligatoria" (Nietzsche, 2015, pp. 24-25): el poder legislativo del lenguaje proporciona las primeras leyes de verdad y mentira. El lenguaje es establecido socialmente con sus reglas semánticas y sus funciones cognoscitivas, naciendo como "cristalización arbitraria de cierto sistema de metáforas que, inventado libremente como cualquier sistema de metáforas, se impuso luego como el único modo públicamente válido de describir el mundo" (Vattimo, 2012, p. 32), con lo cual tenemos que el empuje de un lenguaje que se convierte en "el sistema de metáforas oficial" viabiliza el surgimiento de eso que llamamos sociedad... y de paso, se olvida de que es un sistema de metáforas.

¿Y cómo surgen las palabras? Siguiendo un doble mecanismo: primero, extrapolando un impulso nervioso en una imagen, y segundo, transformando esta imagen en un sonido, y así, de forma instantánea, toda palabra se torna concepto "en tanto que justamente no ha de servir para la experiencia singular y completamente individualizada a la que debe su origen, sino que debe encajar al mismo tiempo con innumerables experiencias, por así decirlo, más o menos similares, jamás idénticas estrictamente hablando." (Nietzsche, 2015, pp. 26-27) Si el mecanismo de surgimiento de las palabras es doble, doble también ha de ser la gratuita pretensión de fundamentación de que los conceptos verbalizados en las palabras designan algo real y nos informan sobre ello: inferir de la dualidad palabracosa la existencia de una causa fuera de nosotros es un uso injustificado del principio de razón cuando lo único que conocemos es nuestro impulso nervioso que activó nuestra fuerza creativa, y atribuir a la comunicación hablada la capacidad de compartir significados objetivos es un exceso autocomplaciente de la razón. En palabras de Fink, "el concepto es la cáscara vacía de una metáfora que en otro tiempo hervía de intuición." (1989, p. 41) La verdad queda, entonces, reducida a aquello que ha sido desde siempre, desde el momento de su nacimiento: "impresión subjetiva nerviosa [que luego es] catapultada mediante la estructura del lenguaje a verdades lógicas conceptuales, a figuras gramaticales, que posteriormente avaladas por el consenso social, se constituirán en «verdad»." (Fava, 2017, p. 185). Así pues, la habitual concepción de la verdad como referencia objetiva es un contrasentido pues en realidad todo es vanidad falsa en nuestras construcciones de significados: este juego de ilusiones lingüísticas "es una forma de «mentira en sentido extramoral»; y «mentir» es simplemente el estímulo consciente e intencional de la ilusión." (Vaihinger, 2015, p. 89) La representación del objeto mentado "está lejos de corresponder fielmente a la percepción originaria, pues constituye una imagen de una imagen de la misma", pero este carácter de imagen de imagen persiste oculto "en los usos conscientes-convencionales que hacemos de las palabras y los conceptos" (Fava, 2017, p. 184). 
Si nuestras expresiones son esencialmente inadecuadas y no hay ningún vínculo entre sujeto hablante y objeto al cual suponemos habitualmente que el sujeto designa con su habla, entonces el lenguaje funciona como un agente violador de la individualidad de cada cosa que genera impresiones en el sujeto, agrupando bajo nombres genéricos a colectividades de individuos que, en el fondo, muestran sus propias particularidades. Y más aún, el lenguaje funciona con fuerzas estáticas, lo cual le impide capturar el flujo de las cosas (si es que algo así era posible, en primer lugar), al modo en que la abeja edifica arquitectónicamente su panal, pero en vez de recurrir a la mera naturaleza, la arquitectura que gesta el hombre se realiza "con la materia más delicada de los conceptos que, desde un principio, tiene que fabricar por sí mismo." (Nietzsche 2015: 30) Strictu sensu, lo que hace el hombre con el lenguaje es establecer un reencuentro con sus propios intereses una vez que su talante creativo ha reaccionado a los impulsos nerviosos sensoriales: "el lenguaje actualiza las cosas, no como son, sino en una perspectiva extraña a ellas", lo cual nos deja con "«metáforas de las cosas», por consiguiente, perspectivas que les son extrañas e inadecuadas." (Conill Sancho, 2007, p. 57) Dejamos a Nietzsche expresarlo con sus propias palabras:

Toda la regularidad de las órbitas de los astros y de los procesos químicos coincide en el fondo con aquellas propiedades que nosotros introducimos en las cosas, de modo que, con esto, nos infundimos respeto a nosotros mismos. En efecto, de aquí resulta que esta producción artística de metáforas con la que comienza en nosotros toda percepción supone ya esas formas y, por tanto, se realizará en ellas; solo por la sólida persistencia de esas formas primigenias resulta posible explicar el que más tarde haya podido construirse sobre las metáforas mismas el edificio de los conceptos. (2015, p. 33)

Solo captamos en las cosas esas formas que ya están supuestas en la producción de esas percepciones instauradas en la mente desde nuestros impulsos nerviosos. Tenemos, pues, que "el conocimiento, ya desde la palabra, es representación en el sentido de que no es una imagen-copia, un espejo o calco de la realidad, sino una nueva presentación, o producción del original" (Fava, 2017, p. 184). Lo que busca el hombre con el lenguaje y el camuflaje de su capacidad creadora bajo el uniforme de la verdad es la utilidad: "el intelecto está al servicio de la voluntad de vivir, descansa en una ilusión que sostiene a la vida." (Fink, 1989 , p. 39) Lo que usualmente llamamos certeza es el olvido de este acto de ilusión, $y$, de hecho, necesitamos ese olvido pues solo nos sentimos cómodos cuando tenemos seguridad sobre el sentido de lo que hacemos. Todo el tiempo estamos haciendo algo, viviendo, practicando un modo de vida: "como no podemos dejar de actuar, tampoco podemos dejar de tener por verdaderos nuestros conceptos y representaciones." (Conill Sancho, 2007, p. 64)

En obras posteriores, Nietzsche sigue incidiendo en el carácter artificial y utilitarista de la verdad. En Humano, demasiado humano (originalmente publicado en 1978 y luego aumentado en las dos siguientes reediciones de los respectivos años sucesivos) ${ }^{3}$, él afirma que todo pensamiento profundo, cuando queda

3 Este libro conforma, junto a Aurora (1881) y La gaya ciencia (1882), la tríada de libros producto de lo que se suele etiquetar como el periodo intelectualista de Nietzsche. 
despojado de la pretensión metafísica de postular un mundo ordenado y un acceso intelectual de nuestra parte hacia él para justificar la objetividad de la verdad, se reduce a un sentimiento intenso "que no garantiza respecto al conocimiento nada más que a sí mismo, tal como la fe intensa no prueba más que su intensidad, no la verdad de lo creído." (I, §15) Al poco rato, añade que "desde hace milenios hemos mirado al mundo con pretensiones morales, estéticas, religiosas, con ciega inclinación, pasión o temor, y nos hemos abandonado a los vicios del pensamiento ilógico, ha devenido poco a poco este mundo tan maravillosamente abigarrado, terrible, profundo en significado, lleno de alma; ha recibido colores, pero nosotros hemos sido los coloristas." (I, §16) Esta grandilocuente expresión se realza oportunamente con la siguiente cita de La gaya ciencia:

Durante mucho tiempo el intelecto no ha producido más que errores. Algunos de ellos resultaron útiles y acertados para la conservación de la especie, pues quien los adoptaba o los heredaba podía luchar con más ventaja por sí mismo y sus descendientes. Tales errores, que al igual que tantos artículos de fe no dejaron de transmitirse por herencia, hasta llegar a ser el fondo común de la especie humana, son, por ejemplo, los siguientes: hay cosas duraderas, cosas idénticas; existen efectivamente objetos, materias, cuerpos, las cosas son lo que parecen ser; nuestro querer es libre, lo que es bueno para mí tiene también una bondad intrínseca. (III, \110)

Queda claro que los artificios del lenguaje responden a nuestro deseo de sustentar justificaciones solventes para lo que hacemos y pensamos, y a su vez, queda también claro que este pathos de la verdad fabricada opera como una creación donde el creador refleja sus propias inclinaciones e intereses. Pero, además, pone al hombre como un ente esencialmente creador, un artista: hay en la concepción nietzscheana del lenguaje una prioridad del pensamiento estético, prioridad fundada en el hecho de que en el arte la creación se muestra a sí misma como tal. Tal como nos lo aclara Vásquez Rocca, "el origen del lenguaje no sigue un proceso lógico, lo que a su vez devela que este material a partir del cual trabaja y construye el hombre la verdad proviene de la imaginación, pero en ningún caso de la esencia de las cosas." (2012, p. 47) El hombre, en el arte, "busca un nuevo campo para su actividad y otro cauce", un campo y un cauce donde "confunde sin cesar las rúbricas y las celdas de los conceptos introduciendo de esta manera nuevas extrapolaciones, metáforas y metonimias." (Nietzsche, 2015, p. 34)

Esas posiciones que usualmente designamos como verdades son en realidad declaraciones del deseo de creer que nuestras designaciones de términos nos remiten a un núcleo esencial del objeto designado, el mismo que proyectamos hacia lo extramental mientras ponemos a lo extramental en una situación de necesario nexo con lo mental, algo propiamente interno del sujeto. Estas «verdades» no responden genuinamente a los estándares de lo verdadero que han imperado por siglos y siglos pues son solamente "ilusiones necesarias -metáforas convenidas, útiles, que se han impuesto-: la causalidad, voluntad libre, leyes naturales, espacio, tiempo, número, átomo, etc. [...], todas éstas son ficciones reguladoras, creencias útiles, mas no verdaderas." (Vásquez Rocca, 2012, p. 47). En la constitución de 
eso que cotidianamente denominamos realidad hay un "añadido humano" o, mejor dicho, un impacto hermenéutico que no puede desprenderse de dicha realidad sin aniquilarla: "este añadido no es otro que el que aporta la interpretación humana a un acontecer mudo." (Gama, 2014, p. 176) Una vez desprovistas de contenido objetivo y de referencialidad firme, la verdad se ve irremediablemente reducida a constructo que carga como única verdad la historia de sus intereses conceptuales inherentes: ése es uno de los puntos centrales a ser reflejados en Humano, demasiado humano, pero, primero, con el fin de atar debidamente algunos cabos, debe surcar un ruedo conceptual a través de sus Consideraciones intempestivas.

\section{La historia como esquema y vehículo de la verdad}

La serie de Consideraciones intempestivas se inició en 1873 con la dupla de "David Strauss, el confesor y el escritor" y "Sobre la utilidad y el perjuicio de la historia para la vida", continuando un año después con "Schopenhauer como educador", y terminando en 1876 con "Richard Wagner en Bayreuth". La segunda y la tercera son las más célebres, y se puede decir que el hilo común de estos cuatro ensayos es el intento de su autor por entender cómo puede la cultura forjar el modo correcto en que el hombre puede afianzar su lugar en el mundo. En "Schopenhauer como educador", por ejemplo, advierte Nietzsche que la filosofía debe tener como función principal el buscar la verdad - sea cual sea ésta - en los cimientos y trasfondos de su propia capacidad crítica: si al Estado nunca le interesa la verdad a secas "sino solo la verdad que le es útil", entonces, "una alianza entre el Estado y la filosofía sólo tendrá sentido si la filosofía puede prometer serle de incondicional utilidad" (2002, p. 164). Pero lo propio de la filosofía es el elaborar una continua dinámica de cuestionamiento a "lo que se sanciona como válido" y a "lo conveniente para el bienestar común" para desentrañar lo que realmente se entiende como lo válido y lo conveniente. Así, la rebeldía nietzscheana para con el statu quo académico se refleja en su propio posicionamiento contra el régimen político, el cual cosifica todo lo que existe en su interior para preservar su sistema político. El filósofo de Röcken exige, pues, a la filosofía que busque una nueva vida fuera de la vendida academia e instaure "un tribunal superior fuera de la universidad que vigile y controle estas instituciones en lo que respecta a la educación que en ellas se imparte" y cuya legitimidad consiste justamente en estar "carente de poder estatal, sin sueldo ni honores de ninguna clase", con lo que sabrá cumplir con su cometido "libre tanto del espíritu del tiempo como del temor a ese espíritu." (Nietzsche, 2002, pp. 166167) Para ello, el enfoque filosófico ha de centrarse en cómo es posible entender al hombre desde su más íntima esencia de proyecto de vida, como entidad capaz de forjar su destino a lo largo del camino de su propia vida en medio de tantos cánones y estándares que articulan el inevitable esquema social y político desde los que se dictamina el entorno donde vive. La Consideración precedente proporciona la estrategia idónea para ello: una aclaración sobre las modalidades de estudio de la historia y sus respectivos intereses.

La historia es el espejo que tiene el sujeto ante sí para interpretar todo lo que hace en tanto que forja su esencia vital a través de todas sus vivencias. Hay tres formas de enfoque histórico: la monumental, la anticuaria y la crítica. La exigencia de una historia monumental necesita, nos dice, «grandes momentos», hechos heroicos que merezcan ser 
recordados por generaciones. La historia monumental sirve, en este sentido, a entregar modelos del pasado que ofrezcan una inspiración a los hombres de acción del presente que buscan cambiar su situación y que aspiran a un cierto grado de felicidad. Porque aquello que es digno de imitar, lo es por haber sido digno de recordarse y, por lo mismo, se ha eternizado en la memoria histórica. Son aquellos ejemplos -de hombres y acciones- que han sobresalido en su época por haberse enfrentado a ella y haberla cambiado, los que deben ser recogidos para realizar nuevas acciones, igualmente dignas de hacerse eternas. Y el obstáculo para esto lo constituyen, nuevamente, la apatía y la rutina, propias de la actitud pasiva común a tantos hombres, esos del rebaño que Nietzsche ha insistido en criticar. Pero a ello se agrega una segunda dificultad, en la medida en que la admiración e inspiración de un cierto pasado debe evitar su degeneración a una imitación exacta, pues, más allá de que la historia se componga siempre de acontecimientos únicos, el hombre de acción debe tender hacia el futuro; y ello se le haría imposible de quedarse en la repetición del pasado. (Huidobro, 2008, p. 65) La exigencia de una historia anticuaria, por su parte, es la una admiración rotunda del pasado que implica un negarse al presente, una carencia de apreciación del arte actual. Venerando los objetos del pasado, el alma del hombre puede verse poseída por éstos. Así, en una piedad extrema, el sujeto se funde con el objeto y pierde, finalmente, su personalidad. Propia de quienes suelen buscar su historia en la de los demás e identificar su existencia con el espíritu del mundo que los rodea, esta actitud se asemeja entonces a aquella de los débiles que asumen la verdad y los valores dados externamente y viven conformes con ellos: de este modo, su existencia goza de una disculpa y de una justificación, proyectando un futuro que emule el pasado con una mentalidad más parsimoniosa que la expuesta en la modalidad monumental. (Huidobro, 2008, pp. 65-66) Las modalidades monumental y anticuaria de la historia se dedican a la «disección histórica», sin más, se niega a dar brillo al presente y deprime: pierden de vista el hecho de que, en cualquier época, el conocimiento del pasado "solo se desea al servicio del futuro y el presente, pero no para la debilitación de este último ni para el desarraigo de un futuro lleno de vitalidad" (Nietzsche, 2010, p. 67).

Frente a eso, hace falta la historia crítica, la que más se ajusta a las exigencias propias del hombre de acción, quien dispone de la fuerza "para destruir y liberarse del pasado" y la puede utilizar de vez en cuando "llevando al pasado a juicio, instruyendo su caso de manera dolorosa para, finalmente, condenarlo, ya que todo pasado es digno de ser condenado, pues así acontece en las cosas del hombre, siempre envueltas en las fuerzas y debilidades humanas." (Nietzsche, 2010, p. 65) Eso sí, también hay que andar con mucho cuidado aquí. ¿No sería acaso un exceso de pensamiento crítico, y, por tanto, una traición a sí mismo, el proyectar un futuro sin conciencia meticulosa del pasado? ¿No conllevaría eso el peligro de la autoproclamación visionaria del destino futuro de un pueblo, una nación, una cultura? Los peligros de la conciencia histórica deben verse en los excesos de la historia anticuaría, crítica y monumental: arcaísmo, presentismo y futurismo, respectivamente: lo que se necesita es alguna síntesis de esas tres maneras de leer el pasado, no un escape del pasado, porque no se puede escapar del pasado. (White, 1992, p. 334) La exigencia propia de la historia crítica es una claridad única de discernimiento, lo suficientemente novedosa como para evitar el hábito 
historiográfico de recoger y adoptar hitos pasados sin cuestionamiento. Apunta a algo inaudito: jugar malabares con la dualidad recuerdo-olvido en nombre de la vida desde su vitalidad más punzante y auténtica. La historia crítica asume conscientemente su dimensión ética como obra de recreación de parte del hombre de acción: se asoma en ella "aquel llamado a cultivar una nueva naturaleza, distinguiendo esos errores a fin de contraponerse a la naturaleza de la que se procede; es el giro de atención hacia el futuro, volviendo necesariamente la espalda al pasado." (Huidobro, 2008, p. 66) El tipo de objetividad en la mirada histórica que aquí se propugna no aspira a establecer justicia: "no es aquí la justicia la que lleva las cosas humanas a juicio [...] sino la vida quien aquí se expresa, ese poder oscuro e incitante, ese poder que con insaciable afán se desea a sí mismo". (Nietzsche, 2010, p. 65)

Es irremediable el confrontarnos continuamente con la historia que antecede a lo que somos y lo que hacemos mientras nos proyectamos hacia el horizonte futuro, pero también hay que remodelar el recuerdo del pasado para discernir, contando con la fuerza de espíritu adecuada, entre aquello que ha de permanecer como inspiración y aquello otro que ha de ser quemado en la hoguera de la nada. La legislación para elaborar discernimientos y otorgar veredictos sobre los fulgores motivadores y los lastres horrendos de las épocas pretéritas se funda en la fuerza que debería tener uno para asumir su propia vitalidad bajo sus propios términos: "se trata del intento de darse a posteriori un pasado del que se quiera proceder frente al pasado del que efectivamente se procede." (Nietzsche, 2010 , p. 66) Es algo muy peligroso y muy desafiante, a la vez que necesario... pero hay que dar la talla para ello: "Si no se es fuerte y no se han tenido las capacidades de romper con el entorno y la tradición, si se vive conforme y «feliz» con el presente de todos, si se es, en fin, parte del rebaño, no puede obtenerse un grado superior que reconozca en una persona el derecho de juzgar otros tiempos. (Huidobro, 2008, p. 67) He aquí el sentido profundo la exhortación que hace Nietzsche a los jóvenes eruditos, los más idóneos para cultivar la historia crítica: "Solo desde la fuerza más poderosa del presente tenéis el derecho de interpretar el pasado, solo a través del máximo esfuerzo de vuestras propiedades más nobles adivinaréis lo que es digno de saberse del pasado, lo que es digno de ser conservado y lo que es grande. iSolo lo semejante conoce a lo semejante! De lo contrario, no haréis otra cosa que descender el pasado a vuestro nivel." (Nietzsche, 2010, pp. 93-94) La emergencia de esta cultura noble solo podrá instaurarse y sostenerse mientras preserva una actitud intransigentemente agonista con el Estado, por lo que debe renunciar a proponerse como idea inspiradora para éste y más bien servir como vigía de sus abundantes loci obscuri (moralización artificial a través de sus instituciones, pretensión de encarnar el espíritu de una nación, opresión, asociación con las élites clericales, etc.): para Nietzsche, en realidad, el Estado no debería inmiscuirse en los asuntos de la cultura pues, aún si actúa de acuerdo a un discurso oficial de la promoción de ideales nobles para el civismo y el amor a la patria, lo hace únicamente de manera indirecta y a pesar de sí mismo (Lemm, 2013, p. 71).

De todos modos, aún a pesar de cometer el pecado capital de usar la historia como mero ejercicio de erudición en nombre de una liturgia adoradora del pasado para certificar una visión autocompasiva del presente y una tarea inauténtica para el futuro, el historiador 
ha de aprovechar el rigor investigador y la meticulosidad metodológica de las historias monumental y anticuaria a fin de cumplir con extrema lucidez con la función de elucidar críticamente lo útil e importante del pasado en función de la vida. Ella contiene estos factores indispensables: criterios éticos en su tarea de discernimiento; formas estéticas para su aplicación a partir de las inquietudes creativas del pensador; una penetrante mirada psicológica en las motivaciones del sujeto; un sigilo constante para no caer en la autocomplacencia, la cual solo abriría la Caja de Pandora de legitimación del statu quo, eso que Nietzsche denomina como exceso de historia. (Huidobro, 2008, pp. 66-68) Así pues, "que la vida necesita del servicio de la historia es algo que debe comprenderse tan claramente como que un exceso de historia daña a lo viviente" dado que la historia pertenece al ser vivo en su triple faceta de "alguien que necesita actuar", "alguien que necesita conservar y venerar" y "alguien que sufre y necesita liberarse." (Nietzsche, 2010, p. 52). La vida del ser viviente evoluciona y se fortalece continuamente mientras va pensando su vida; ese pensar su vida es ya vivirla, entender las metas, sentimientos y motivaciones que le dan un norte y una estructura, eso sí, un norte y una estructura sin firmezas garantizadas. Ni siquiera hay en eso que llamamos yo una unidad legítimamente establecida, pero motiva una noción sujeta a ser una y otra vez reinterpretada con la fuerza de voluntad histórica. Esto mismo se nos reitera con otras palabras por vía de Vásquez Rocca:

La utilidad para la conservación -y no una necesidad abstracta y teórica de no ser engañadose sitúa como motivo detrás de la evolución de los órganos de conocimiento. Por tanto, el sujeto no es nada dado, sino tan sólo algo "añadido, imaginado, supuesto debajo" y que proporciona la ilusión de un punto de referencia estable en medio del devenir universal. El yo es algo puesto por el pensamiento, una creencia falsa que obtiene su valor y su firmeza del hecho de constituir una condición de vida, pero que en sí tan sólo es la generalización ficticia del sentimiento de vivir. (2012, p. 51)

Así pues, la historia crítica juega con nuestra necesidad de olvido y con la destrucción del olvido, exige sacar el máximo provecho del dinamismo inherente a la fuerza plástica de la vida, tal como se da en un pueblo y en un individuo. Así, la historia crítica puede ser vista como la doble tarea de luchar contra "lo inculcado de tiempo atrás" y de revertir la tendencia para "implantar una nueva costumbre", logrando con ello evitar las falencias de las otras dos modalidades de historia y el exceso de la autosuficiencia, el mismo que contradiría y oprimiría a la misma vida que la crea (Frey, 2015, pp. 282-3). Bien utilizada, la historia crítica es, indispensablemente, la pauta intelectual más idónea, la auténticamente leal a la vida pues decide en cada una de sus intervenciones hermenéuticas qué hitos del pasado son los definitorios del "aquí y ahora".

La actitud crítica es la propiamente filosófica: remueve la losa del proceso histórico que no deja aflorar la vida, hace a un lado el pasado y construye un nuevo origen. A través de la memoria crítica relega todo lo que frene el olvido $\mathrm{y}$, al hacerlo, se pone al servicio de la vida. (Frey, 2015, p. 285) Esta vida está plagada de fuerza plástica: por fuerza plástica, Nietzsche entiende "esa fuerza para crecer por sí misma, ese poder de transformar 
y asimilar lo que es pasado y extraño, de sanar las heridas, de reemplazar lo perdido, regenerar las formas destruidas" (2010, p. 43). Dicho con otras palabras, se trata de la capacidad de asimilar el pasado al servicio de la vida de tal modo que no se reduzca a una especie de conocimiento interno, sino que pueda externarse de manera creativa mientras reconoce el impulso que la inspiró, impulso que escoge qué evocar y qué borrar. Así, esta capacidad se erige en el elemento crucial para dar forma a la historia pues ella, a despecho de lo que pretendan ciertas formas de Razón Ilustrada o el idealismo histórico de raíz hegeliana, no puede explicarse como logos de sí misma (Frey, 2015 , p. 284). Tal vez nuestro filósofo de Röcken no tenía plena conciencia de esto, pero queda claro que en esta Segunda intempestiva hay una directa declaración de principios sobre el leit-motiv del legado central de toda la filosofía nietzscheana: una mirada implacablemente crítica a la psique de los hombres y las sociedades con miras a hacer un incansable ajuste de cuentas contra todas las tradiciones de las diversas formas de cultura, eso que varias veces denominaba genéricamente como moral de trasmundo. ${ }^{4}$

\section{La historia orientada hacia la vida, la nueva misión de la filosofía}

El libro Humano, demasiado humano es un ejercicio cautivador y embriagador de análisis genealógico de todas las provincias conceptuales supuestamente "conquistadas" por las diversas cruzadas conformadas por ejércitos de pensadores de la pretendida aeterna veritas. Su estrategia para ello es tripartita: 1) interpretar el sentido de los ideales en base a su origen; 2) detectar a lo contrario como fuente auténtica de dicho origen; 3) desvelar el vacío subyacente a todo "idealismo". La primera parte del libro, titulada "De las cosas primeras y últimas", se vuelca contra el designio de una estructura universal del mundo para justificar la fundamentación de la ciencia y la lógica desde lo metafísico, o sea, la noción de una persistencia autosuficiente en el mundo y su correspondiente asequibilidad a una también persistente arquitectura de la razón. Mas toda esta grandilocuencia no está justificada en el éxito de la búsqueda de la verdad; por el contrario, es el síntoma patético de la falta de sentido histórico de parte de la academia filosófica, cuyos eruditos están demasiado cegados para advertir que "todo ha devenido, no hay datos eternos, lo mismo que no hay verdades absolutas." (HDH, I, \$2) Una manifestación burda y risible de esta pretensión está en el modo tan ingenuo en que se cree que el fenómeno lingüístico está equipado para expresar y justificar algo metafísicamente fijo: "La importancia del lenguaje para el desenvolvimiento de la cultura radica en el hecho de que en él el hombre puso un mundo propio junto al otro, un lugar que consideraba tan firme como para, a partir de ahí, levantar sobre sus goznes el resto del mundo y adueñarse del mismo." (HDH, I, \$11) Yendo más al fondo de la cuestión, Nietzsche denuncia la costumbre filosófica de larga data de "situarse ante la vida y la experiencia como ante un cuadro desplegado de una vez y por todas y que mostrase invariablemente, la misma escena", exigiendo que dicha escena sea interpretada correctamente "para así inferir la esencia que ha producido el cuadro, o sea, la cosa en sí." (HDH, I \$36) Los ecos de la primera parte de Sobre verdad $y$ mentira en sentido extramoral resuenan cuales épicos truenos en estas líneas, esta vez con un talante "trascendental" más acentuado.

4 Término que aparece varias veces en La gaya ciencia, Así habló Zaratustra, así como su trilogía de Más allá del bien y del mal, La genealogía de la moral y Crepúsculo de los ídolos... y cómo no, en sus recuentos de estos libros y sus ideas centrales en las dos últimas secciones de Ecce homo. 
Las dos partes siguientes se titulan "Para la historia de los sentimientos morales" y "La vida religiosa", respectivamente, apuntando ambas a una denuncia paralela sobre la negatividad de lo metafísico, esta vez en torno a lo que usualmente denominamos como conciencia moral y virtud: sin la justificación de lo metafísico, la tradición de esos conceptos se revela como una serie de máscaras traidoras a la vida; ante eso, se apela a un develamiento de los miedos y ansiedades que llevaron a crear tales máscaras. Con las partes cuarta y quinta ("Del alma de los artistas y escritores" e "Indicios de cultura superior e inferior"), se engarza la cosecha de denuncias de las dos partes precedentes con las inquietudes nietzscheanas ya plasmadas en sus Intempestivas segunda y tercera. También merece una mención especial la octava parte "Una ojeada al Estado", la cual congrega acusaciones diversas a varios aspectos del entramado socio-político moderno así como de los movimientos reformistas de aquel entonces, denunciándose los tipos de hipocresía que subyacen a todas estas posiciones. ${ }^{5}$ Años más tarde, el filósofo de Röcken expresará su orgullo de lo que ha logrado en este libro en este pasaje del tercer capítulo de su autobiografía Ecce homo: "el título dice «donde vosotros veis cosas ideales, veo yo - icosas humanas, ay, demasiado humanas!»... Yo conozco mejor al hombre... la expresión «espíritu libre» quiere ser entendida aquí en este único sentido: un espíritu devenido libre, que ha vuelto a tomar posesión de sí." (III, sección 3, §1)

Nietzsche se aboca a pasos de gigante hacia "el filosofar «histórico», que no cree tan fácilmente en «hechos eternos» y en «verdades absolutas», y que concibe al hombre como un resultado de procesos históricos", y es con este enfoque que "el filosofar debe ser analítico e histórico y, con ello, «científico»." (Fink, 2000, p. 54) Es así como él se focaliza con creciente ardor en la labor filosófica como crítica de la ideología al desplazar "el contenido expreso y autoconvincente de las ideas hacia una intencionalidad más poderosa y abarcativa que, por estar encubierta, sólo puede ser desenmascarada por un análisis exhaustivo." (Frey, 2005, p. 117) Es que la máscara no puede evitar ser vista como tal cuando llega el momento en que la reflexión filosófica sobre el significado de los valores se detiene con firmeza ante las pretensiones de éstos. Si mantenemos nuestros estándares conceptuales atrapados bajo la perversamente metafísica hipnosis de la propuesta de que la realidad y la verdad se hallan en el "en sí", entonces solo queda derivar de la fatalidad artificiosa que Nietzsche propugna para el fenómeno lingüístico que solo tenemos a nuestro alcance imágenes que desfiguran y distorsionan a la supuesta realidad, pero si le damos un enfoque diferente fuera de esa hipnosis, en estricta coherencia con la exigencia de una radical renovación de la filosofía, entonces vemos que el lenguaje crea mundo y crea vida (Conill Sancho, 2007, pp. 48-50). Al negar la dicotomía cosa en sí-fenómeno con su consecuente diferenciación jerárquica, el pathos ilustrado de Humano, demasiado humano enuncia una orgullosa declaración de guerra contra el doblamiento idealista del mundo, contra la "manía de los trasmundos" (Fink, 2000, p. 53). Crear conceptos es crear, en simultáneo, modos de vida que se justifican bajo ellos mismos: entender y asumir esto implica una lucha contra la tradición del pensamiento metafísico que, por ser demasiado larga, resulta muy pesada y hasta muy neurótica... pero es una labor bélica indeclinable. En palabras de Nietzsche, volviendo a su Ecce homo, una labor filosófica de esta índole

5 En buena medida, esta secuencia temática habrá de repetirse en Más allá del bien y del mal (1886). 
"es la guerra, pero la guerra sin pólvora y sin humo, sin actitudes bélicas, sin pathos ni miembros dislocados, todo eso sería aún idealismo. Un error detrás del otro va quedando depositado sobre el hielo, el ideal no es refutado - se congela... Aquí, por ejemplo, se congela «el genio»; un rincón más allá se congela «el santo», bajo un grueso témpano se congela «el héroe»; al final, se congela «la fe», la denominada «convicción», también la «compasión» se enfría considerablemente - casi en todas partes se congela «la cosa en sí»..." (III, sección 3, 『1)

Tal como señala con suma precisión Fink, lo fundamental de este enfoque psicologizante nietzscheano consiste "en interpretar la "genealogía» del ideal desde su contrario: el derecho tiene su origen en el provecho común; la verdad, en el instinto de falsificación, de engaño; la santidad, en un trasfondo muy poco santo de instintos y de rencores" (2000, p.55), lo cual se traduce en un develamiento de ese gran embuste que se puede designar genéricamente como idealismo. Al ilustrar psicológicamente la religión, el arte, la moral, Nietzsche cree que en el futuro la metafísica se volverá banal, más aún, carecerá de interés, pues "la metafísica solo tiene importancia para la vida cuando se encuentra vinculada a propósitos fundamentales del corazón humano, cuando ofrece a éstos el armazón conceptual. Disociada de ellos, se convierte en el caprichoso giro en el vacío de un pensamiento que no tiene ya base alguna." (Fink, 2000, p. 57)

Despojada de sus pretensiones de ejercicio racionalista primordial, la metafísica se revela como una caricatura de pensamiento, ya no un instrumento vital para el hombre sino una modalidad fantasmagórica de la autointerpretación de éste, "la ciencia que trata de los errores fundamentales del hombre, pero como si fuesen verdades fundamentales." (HDH, I, \$18) El saber ha de reflejar y motivar la vida de donde él surge: por tener el imperativo de vivir, el ser humano busca siempre conectarse estrechamente con sus propios intereses existenciales, por lo que el filósofo ha de aclarar que toda epistemología debe partir de esta realidad $y$, por consecuencia, elaborar un enfoque científico centrado en la apertura espiritual desde donde se fluya el constante cuestionamiento de sus opiniones, no en busca de una superación de ellas para llegar a intelecciones objetivas, sino para mantener viva la llama del pensamiento de un espíritu auténticamente libre (Little, 2004, pp. 83-85).

Desde la filosofía nietzscheana, el hombre es concebido como animal de ideales y la única antropología consecuente con dicha concepción, la antropología solo puede ser crítica pues ha de descubrir los instintos disimulados que les dieron vida. Dicha antropología ha de sostenerse sobre "la psicología de sus ilusiones, es decir, de la metafísica, la religión, el arte, la moral, la cultura", la cual "interpreta al hombre desde sus grandes proyectos" pero, además "incluso en su forma desilusionadora de ilustración psicológica, el tema exclusivo de Nietzsche es la grandeza de la existencia." (Fink, 2000, p. 59) Nietzsche está ya preparado para dar un salto más allá de sus filudas intuiciones filosóficas de raíz filológica respecto a la verdad como creación lingüística: esta creación puede ahora reclamar el título de nueva verdad: "De las pasiones nacen las opiniones; la inercia del espíritu petrifica éstas en convicciones. Pero quien se sienta espíritu libre, incesantemente vivo, puede impedir esta petrificación. [...] 
Redimidos del fuego, andamos entonces, impulsados por el espíritu, de opinión en opinión, cambiando de partido, como nobles traidores de todas las cosas que, a fin de cuentas, pueden ser traicionadas, y, pese a todo, sin sentimiento de culpa." (HDH, IX, 5637) Lo genuino no es, pues, lo carente de máscaras sino la máscara que valiente y gallardamente saca lustre a sus galones de embuste y falacia que le impuso el tribunal de la verdad tradicional: ya el título del parágrafo 33 de Humano, demasiado humano enuncia el lema de esta posición (aunque todavía sin desarrollarlo como se hará desde La gaya ciencia en adelante) - El error sobre la vida, necesario para la vida. Ésta es su primera frase: "Toda creencia en el valor y la dignidad de la vida estriba en un pensamiento viciado". En el parágrafo siguiente, el último de la primera parte, Nietzsche se pregunta en voz alta si la desesperación es el único resultado realista y viable que procede de la destrucción de todos los fantasmas históricos de esas concepciones de verdad y ciencia que debemos dejar atrás. La respuesta es que eso dependerá sola y exclusivamente del temperamento de la persona que ejercite ese pensamiento crítico: "Un hombre que se ha zafado de las cadenas corrientes de la vida hasta tal punto que solo vive para conocer cada vez mejor, debe poder renunciar, sin envidia ni desesperación, a muchas cosas [...]; le debe bastar con ese libre, intrépido planear sobre hombres, costumbres, leyes y las estimaciones tradicionales de las cosas." (HDH, I, §34) La nueva verdad emerge del cuidadoso y detenido, que nunca definitivo, análisis introspectivo de la voluntad individual que ve en sí misma un indicio razonablemente fiable de las pulsiones de todas las voluntades, y solo así puede cumplir esa verdad con su función nuclear: aliviar la carga de la vida y reconocerse como creación de mascaradas (HDH, II, \$35-38). Este rigor psicológico es algo necesario: la pregunta es si reporta a los hombres más provecho que desventaja o viceversa, una cuestión que solo comenzará a ser abordada explícitamente (a favor de la primera alternativa) desde La gaya ciencia en adelante.

El renovado y ya bien encauzado programa nietzscheano, correspondiente a una filosofía histórico-crítica como resultado de la reflexión, formula que "no existen hechos eternos ni verdades absolutas", de lo que se desprende que todo ha devenido y, "en consecuencia, el filosofar histórico se vuelve a partir de ahora necesario, y con él la virtud de la modestia." (HDH, I, §2) De este modo, se concreta con sigilo la misión propia del pensamiento histórico: referirse a todo lo que condiciona el surgimiento de un cuestionable estado de cosas (Fray, 2005, p. 117). Tal como advertirá Nietzsche unos pocos años después en La gaya ciencia, el libro de 1882 que cierra la trilogía de su periodo intelectualista, al utilizar los preceptos habituales de la tradición filosófica, hay que ver los lances desafortunados y las excepciones que ocurren en ese orden del mundo que nos instruyen habitualmente a construir en nuestras mentes como expresiones de censura que el hombre se hace a sí mismo, las cuales busca justificar en base a ese pretendido orden del mundo: "Cuidado con achacarle crueldad e irracionalidad o lo contrario de lo uno y lo otro: no es perfecto, hi hermoso, ni noble, ni aspira a ninguna de estas cualidades, ino tiene en absoluto el propósito de emular al hombre! iNo lo afectan en absoluto ninguno de nuestros juicios estéticos o morales!" (III, \$109) ${ }^{6}$ No,

6 Más adelante, en la misma obra, el filósofo de Röcken enfatiza que si todo saber es una explicitación de un ajuste de cuentas específico que llama la atención del yo al mirarse a su espejo curtido por la historia, entonces queda claro que "la fuerza de los conocimientos no reside en su grado de verdad, sino en su antigüedad, en su asimilación, en su carácter de condición vital." (III, \110) 
son solo cosa nuestra, algo que brota de nuestro interior, una interioridad que es intelecto al servicio de nuestro deseo de comprendernos a nosotros mismos. iLa comprensión como pulsión!

\section{Conclusión}

No hay nada más allá de esta particularidad concreta en que vivimos y pensamos lo que vivimos (dos cosas que son lo mismo): solo hay esto, e incluso esto pasa por el filtro del lenguaje, cuya función única es la de crear significados a través de metáforas que el sujeto utiliza para verse y comprenderse en un momento determinado de su vida. Para reforzar esto que se vive hoy, hay que tomar plena conciencia de que no hay nada más allá, hay que señalar, denunciar y juzgar esa nada, ponerse la toga del juez nihilista. Pero, que quede bien claro esto: Nietzsche es, ante todo, antinihilista. El nihilismo es su hermenéutica radical que busca destruir las máscaras y pretensiones de todos los ídolos de las diversas formas de la cultura tradicional. Si hay un nihilismo que Nietzsche asume como labor y pauta de su labor filosófica crítica que niega radicalmente la concepción moralista del mundo y de la vida, lo hace para agitar las aguas de la conciencia a fin de que ésta no caiga (mejor dicho, recaiga) en la desesperación y la inercia; por eso también hay un nihilismo afirmativo que antepone la imposición de la vida como flujo continuo de la persistencia del existir ante la nada más allá de ella. Es una hermenéutica que no se limita a negar el vacío sobre el que la moral tradicional ha proyectado un pretendido referente de valoración, sino que afirma la vida: hay que definir a dicha hermenéutica por lo que es, no por lo que no es. No es nihilismo, es vitalismo, y como tal, se desarrolla para desentrañar y ensalzar lo más antinihilista que hay: la celebración de la vida por la vida misma. (Fink, 200, pp. 166-170, 180-7) Tal como el propio autor nos reclama con sus propias palabras, la misión principal de la filosofía es la de preparar el pronto arribo del hombre del futuro, "este hombre del futuro, que nos liberará por igual del ideal existente hasta ahora como de lo que hubo de surgir de él, de ese gran asco, de esa voluntad de la nada del nihilismo; esa campanada del mediodía y de la gran decisión, que vuelva a liberar la voluntad, que devuelva a la tierra su rumbo y al hombre su esperanza; ese anticristo y antinihilista, ese vencedor de Dios y de la nada." (EH, sección II, \$24). Se puede apreciar a Humano, demasiado humano como el manto nocturno donde las estrellas lingüísticas ostentan su luz irremediablemente antropomórfica; también se le puede apreciar como el sol primaveral que agiliza el periodo de cosecha para los frutos histórico-críticos sembrados por la intempestiva maquinaria del hombre de nuestros tiempos. Ha sido nuestra intención mostrar cómo la secuencia de estos tres textos en los cuales hemos centrado nuestra atención asienta y fertiliza de a pocos el terreno donde Nietzsche habrá de sembrar y cosechar su ideario filosófico vitalista.

\section{BIBLIOGRAFÍA}

\section{Fuentes primarias. -}

Nietzsche, F. (2015) Sobre verdad y mentira en sentido extramoral. Madrid: Tecnos.

(2013a) Humano, demasiado humano. Madrid: Ediciones Akal.

(2013b) Ecce homo. Madrid: Alianza Editorial.

(2011) La gaya ciencia. Madrid: Ediciones Akal. 
(2010) Sobre la utilidad y el perjuicio de la historia para la vida: Segunda intempestiva. Madrid: Biblioteca Nueva.

(2002) Consideraciones intempestivas. Madrid: Alianza Editorial.

\section{Fuentes secundarias. -}

Conill Sancho, J. (2007) El poder de la mentira. Nietzsche y la política de la transvaloración. Madrid: Tecnos.

Fava, F. (2017) "Orígenes de la crítica nietzscheana del conocimiento a partir del lenguaje." En Revista de Filosofía Open Insight, vol. VIII, no. 13, enero-junio, 2017, pp. 161-188.

Fink, E. (2000) La filosofía de Nietzsche. Madrid: Alianza Editorial.

Frey, H. (2015) "Nietzsche: la memoria, la historia: la Segunda intempestiva, entre la crítica al historicismo y la negación de la filosofía de la historia." En Cuicuilco, Vol. 22, No. 64, México, sep/dic, 2015, pp. 271-290.

(2005) "Los escritos de Nietzsche como Escuela de la Sospecha." En Cuicuilco, Vol. 12, No. 33, enero-abril, 2005, pp. 113-126

Gama Barbosa, L. E. (2014) "Nietzsche y la vida interpretante." En Praxis Filosófica, no. 39, julio-diciembre, 2014, pp. 171-196.
Huidobro Salazar, M. G. (2008) "Friedrich Nietzsche: la historia al servicio de la vida." En Intus-Legere Historia, Vol. 2, No. 1, pp. 59-71.

Lemm, V. (2013) Nietzsche y el pensamiento político contemporáneo. Santiago: F.C.E.

Little, R. (2004) "El problema del conocimiento en la filosofìa de Nietzsche en el período intelectualista (1876-1882). En Tabula Rasa. Revista de Humanidades, No. 2, enero-diciembre, 2004, pp. 79-92.

Reale, G. y D. Antiseri. (1988) Historia del pensamiento filosófico y científico, tomo I. Barcelona: Herder.

Vaihinger, H. (2015) "La voluntad de ilusión en Nietzsche." En NIETZSCHE, Friedrich. Sobre verdad y mentira en sentido extramoral. Madrid: Tecnos, pp. 85-119.

Vásquez Rocca, A. (2012) "Nietzsche: de la voluntad de poder a la voluntad de ficción como postulado epistemológico. En Nómadas, no. 37, octubre 2012, pp. 41-53. Universidad Central, Bogotá, Colombia.

Vattimo, G. (2012) Introducción a Nietzsche. Barcelona: RBA.

White, H. (1992) Metahistoria. La imaginación histórica en la Europa del siglo XIX. F.C.E., México. 